\title{
Spectrophotometric Determination of Olmutinib in Bulk by Area under Curve and First Order Derivative Methods and its Validation as per ICH guidelines
}

\author{
Balu S. Khandare*, Atish C. Musle, Sanket S. Arole, and Pravin V. Popalghat
}

Kasturi Shikshan Sanstha College of Pharmacy Shikrapur Pune, Maharashtra, India-412208

\begin{abstract}
Abstract: A simple, precise and economical UV-spectrophotometric method has been developed for the estimation of Olmutinib from bulk. Two methods were developed First method (A) applied was area under curve (AUC) in which the area was integrated in wavelength from 262$272 \mathrm{~nm}$. Second method (B) was first order derivative spectrometric method. In this method absorbance at $\lambda \min =256.57 \mathrm{~nm}, \lambda \max =282.83 \mathrm{~nm}$ and zero cross $=267.68 \mathrm{~nm}$ was measured. Calibration curves were plotted for the method by using instrumental response at selected wavelength and concentration of analyte in the solution. In both the methods, linearity was observed in the concentration range of $2-12 \mu \mathrm{g} / \mathrm{ml}$ at the $\lambda \max =267.68 \mathrm{~nm}$. Accuracy and precision studies were carried out and results were satisfactorily obtained. The drug at each of the $80 \%$, $100 \%$ and $120 \%$ levels showed good recoveries that is in the range of 98.00 to $99.00 \%$ for both methods, hence it could be said that the method was accurate. Limit of detection (LOD) and limit of quantitation (LOQ) were determined for the method. The method was validated as per International Conference on Harmonization. All validation parameters were within the acceptable limit. The developed method was successfully applied to estimate the amount of Olmutinib in pharmaceutical formulation.
\end{abstract}

Keywords: UV spectroscopy, validation, Assay, Precision, \% Recovery, Olmutinib.

Article Info: Received 11 July 2019; Review Completed 24 Aug 2019; Accepted 26 Aug 2019; Available online 30 Aug 2019

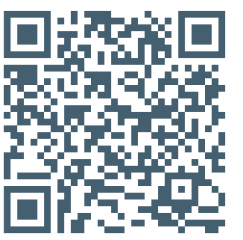

\section{Cite this article as:}

Khandare BS, Musle AC, Arole SS, Popalghat PV, Spectrophotometric Determination of Olmutinib in Bulk by Area under Curve and First Order Derivative Methods and its Validation as per ICH guidelines, Journal of Drug Delivery and Therapeutics. 2019; 9(4-A):349-354 http://dx.doi.org/10.22270/jddt.v9i4-A.3466

Balu S. Khandare, Kasturi Shikshan Sanstha College of Pharmacy Shikrapur Pune, Maharashtra, India-412208

\section{INTRODUCTION:}

Epidermal growth factor binds with high affinity to epidermal growth factor receptor (EGFR) upon cell surface, activates the intrinsic protein-tyrosine kinase activity of receptor, initiating signal transduction cascade results in various biochemical changes in the cell - rises calcium levels, increased protein synthesis and increases expression of certain genes. Eg.gene of EGFR leads to DNA synthesis and cell proliferation. Mutations of EGFR expressions or activity results are in cancer. ${ }^{1}$

Olmutinib N-(3- ((2-)( 4-(4-methylpiperazin-1yl)phenyl)aminao)thieno[3,2-d]pyrimidin-4-

yl)oxy)phenyl)acrylamide.

Olmutinib is an oral epidermal growth factor receptor tyrosine kinase inhibitor (EGFR TKI) of third generation which is being developed by Boehringer Ingelheim and Hanmi Pharmaceutical Co. Ltd to treat non-small-cell lung cancer (NSCLC). Olmutinib binds covalently and inhibits activating EGFR mutations and overcoming
T790Mresistance mutation (mutation of epidermal growth factor receptor). 2,3

In the present study, we developed a novel analytical method and validation of first derivative method for Olmutinib in bulk using UV spectroscopy.

Literature survey reveals that a few spectrophotometric, RPHPLC methods are reported for the estimation of Olmutinib in combination with other drugs. 4<smiles>C=CC(=O)Nc1cccc(Oc2nc(Nc3ccc(N4CCN(C)CC4)cc3)nc3ccsc23)c1</smiles>

Fig 01: Chemical Structure of Olmutinib 


\section{MATERIALS AND METHODS:}

The Olmutinib was kindly supplied as a gift sample by Mylan laboratories pvt.ltd., Hyderabad (India). All rest of chemicals used were of HPLC grade. A double beam UV-Visible spectrophotometer, (UV 1800, Shimadzu limited, Japan) having two matched cells with $1 \mathrm{~cm}$ light path. A citizen analytical balance (Sartorius) was used for weighing the bulk sample.

\section{Preparation of standard stock solutions:}

Standard solution of Olmutinib was prepared by transferring accurately weighed $10 \mathrm{mg}$ of drug into a $100 \mathrm{ml}$ volumetric flask and the volume was made up to $100 \mathrm{ml}$ using methanol as a solvent to get the concentration of $100 \mu \mathrm{g} / \mathrm{ml}$.

\section{Selection of wavelength for analysis of Olmutinib:}

Accurately pipette out $1.0 \mathrm{~mL}$ volume of standard stock solution of Olmutinib was transfer into a $10 \mathrm{~mL}$ volumetric flask, diluted up to a mark with methanol to give concentration of $10 \mu \mathrm{g} / \mathrm{ml}$. The resulting solution was scanned in the UV range (200-400 nm) using Shimadzu UVVIS spectrophotometer instrument. The maximum absorbance of solution was measured at the wavelength 267.68nm (Figure 2).

\section{Preparation of calibration curve:}

From the standard stock solution fresh aliquots were pipette out and suitably diluted with methanol to get final concentration in the range of $2-12(\mu \mathrm{g} / \mathrm{ml})$. The solutions were scanned under 200-400 nm wavelength range and a sharp peak was obtained at $267.68 \mathrm{~nm}$ (figure 2). Calibration curve was plotted by taking absorbance on y-axis and concentration of solution on x-axis (figure 03 and 04). For both the methods A and B. The drug follows linearity in the concentration range $2-12 \mu \mathrm{g} / \mathrm{mL}$ with a correlation coefficient of Method A value ( $\left.\mathrm{R}^{2}\right) 0.999$ and Method $B$ value $\left(R^{2}\right) 0.997$.

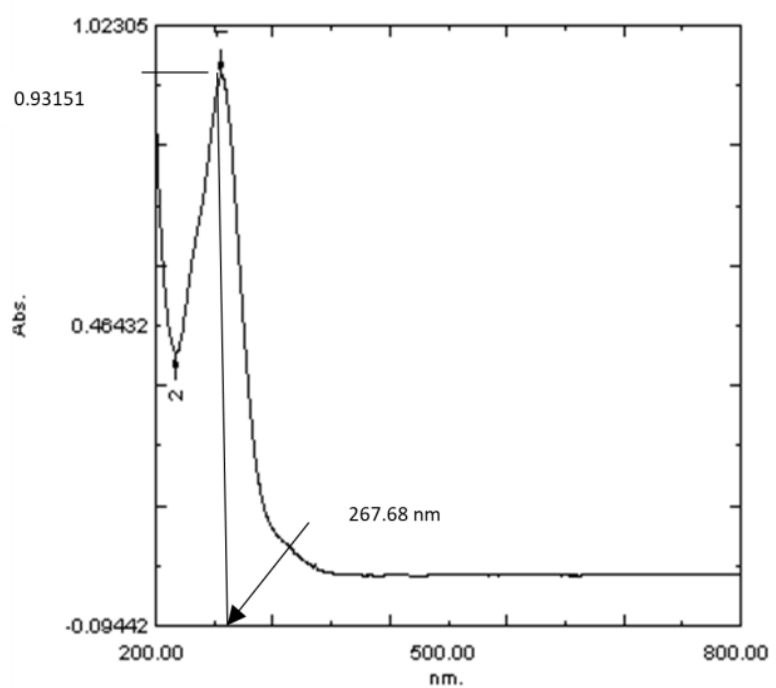

Fig 02: Determination of $\mathrm{C}_{\max }$ of Olmutinib std. stock solution

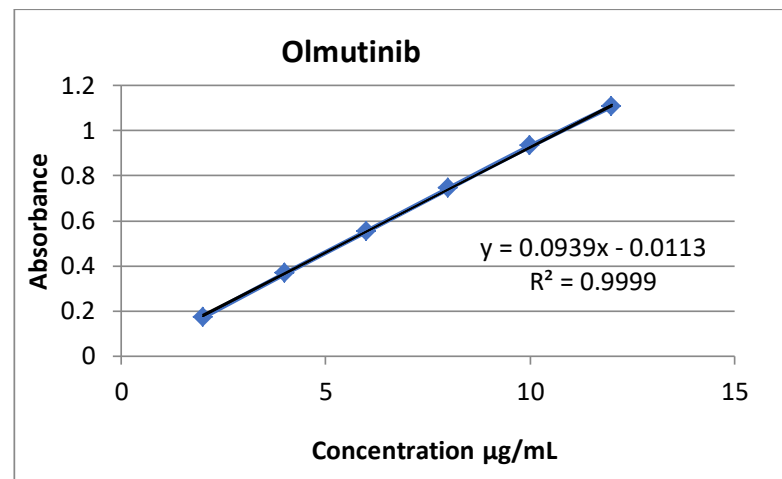

Fig 03: Calibration curve AUC of Olmutinib

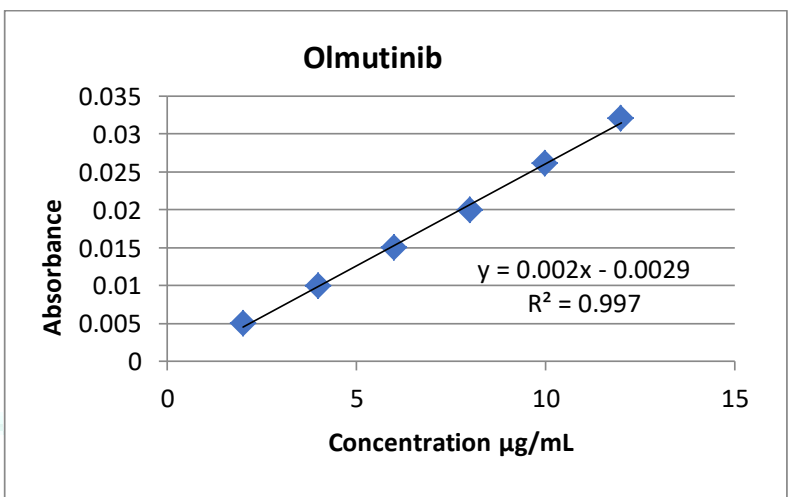

Fig 04: Calibration curve First order derivative of Olmutinib

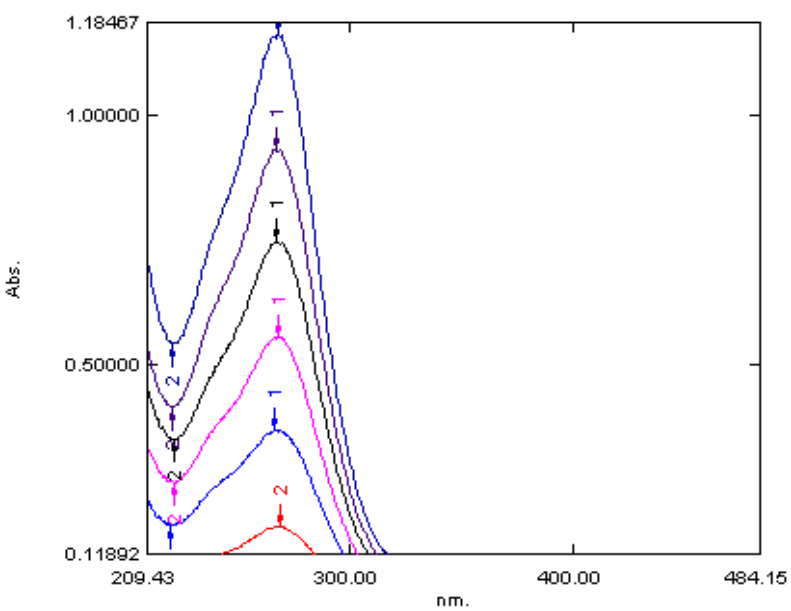

Fig 05: Overlay of Olmutinib showing linearity as increasing concentration.

\section{Area under curve (Method A):}

In area under curve method involves to calculation of integrated value of absorbance with selected wavelength. Area calculation calculated in bounded by the curve and horizontal axis. Horizontal axis represent baseline. Where, $\alpha$ is area of bounded portion by curve data and a straight line connecting the starting and end point and $\beta$ is the area of portion bounded by straight line connecting starting and end point on curve data and horizontal axis, $\lambda_{1}$ and $\lambda_{2}$ are wave length showing starting and end point from figure 6 . In this AUC method area was integrated between the wavelength ranges from 262-272nm (figure 6). Also, calibration curves of Olmutinib was prepared in various concentration ranges i.e. $2-12 \mu \mathrm{g} / \mathrm{mL}$ at their respective AUC range.5,6

$$
\text { Area calculation }(\alpha+\beta)=\frac{\lambda 1}{\lambda 2} \operatorname{Ad} \lambda
$$




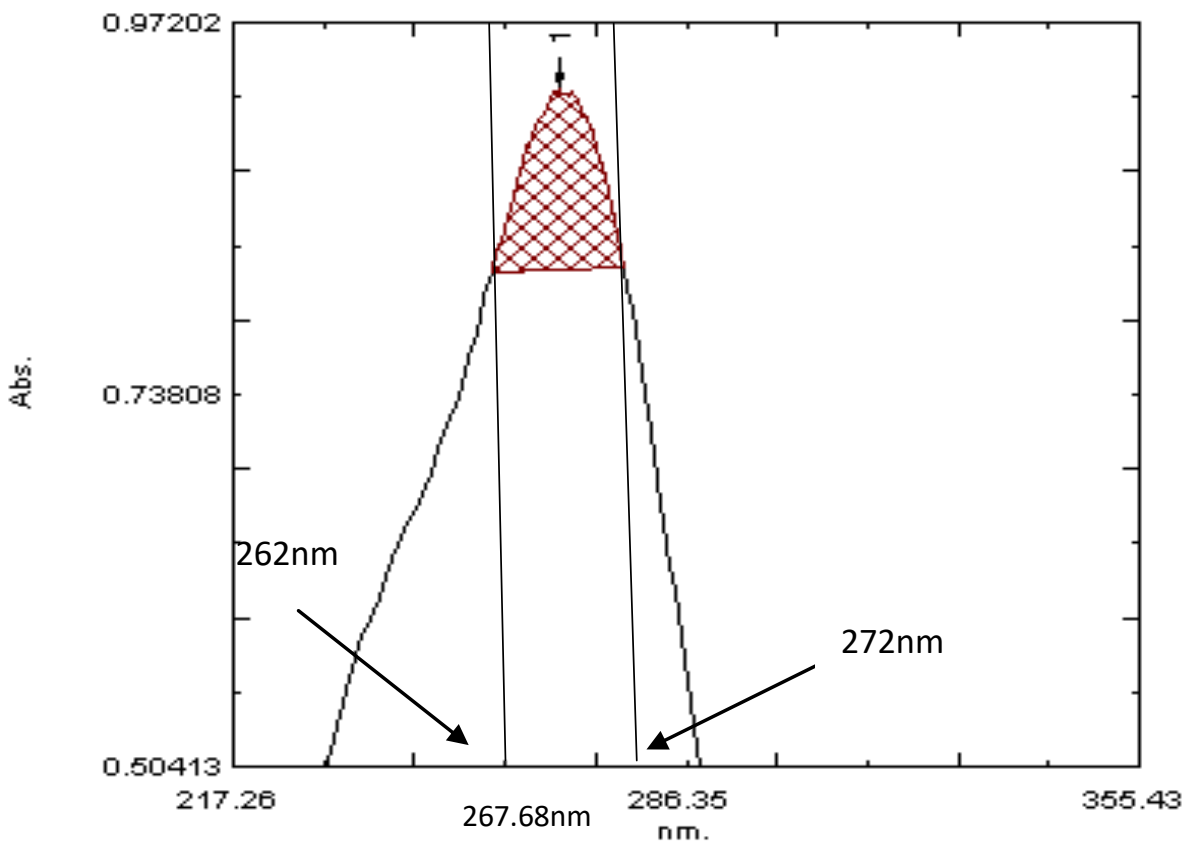

Fig 06: Area under curve graph of $10 \mu \mathrm{g} / \mathrm{mL}$ Olmutinib

\section{First Order Derivatives Spectrophotometry (Method B):}

In this method solution of Olmutinib $(2-12 \mu \mathrm{g} / \mathrm{ml})$ were prepared by appropriate dilution of standard stock solution and scanned in the spectrum mode from $400 \mathrm{~nm}$ to $200 \mathrm{~nm}$. The absorption spectra obtained were derivatised from first fourth order. First order derivative spectra were selected for analysis of drug. From spectra of drug the absorbance was measured at $\lambda \max =2582.83 \mathrm{~nm}, \lambda \min =256.57 \mathrm{~nm}$ and zero cross $=267.68 \mathrm{~nm}$, amplitude difference $(\mathrm{dA})$ with respect to wavelength difference $(\mathrm{d} \lambda)$ was measured for the respective concentration of standard and was plotted against concentrations and regression equation was calculated.7, 8

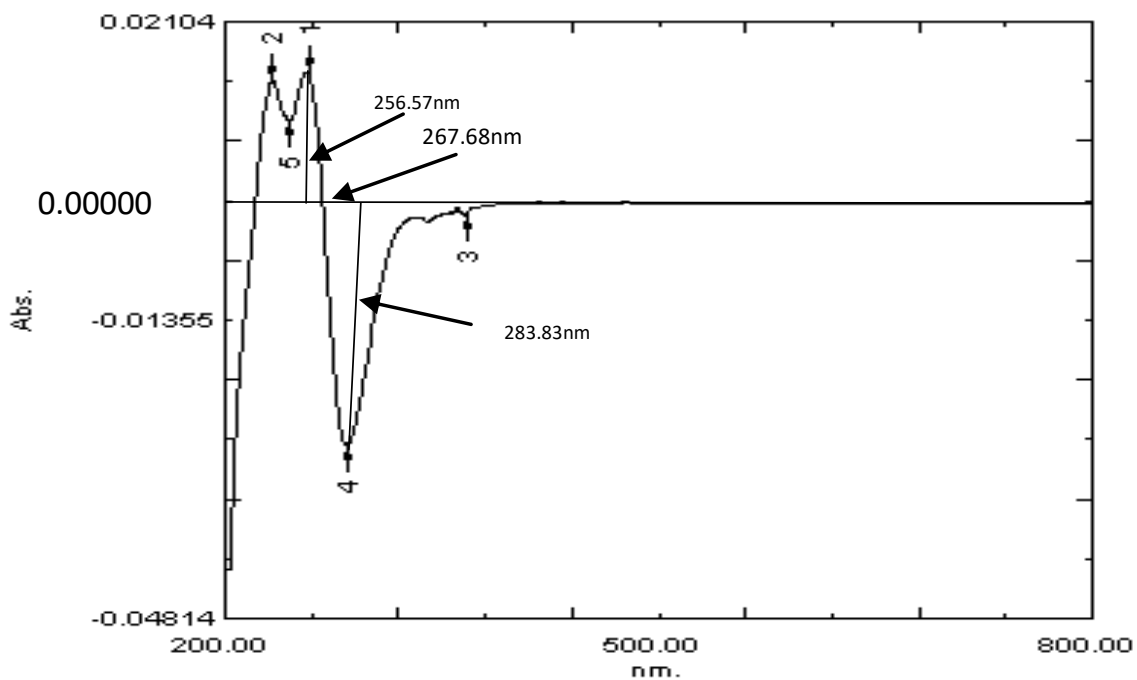

Fig 07: First Order Derivative spectra of Olmutinib

\section{Validation of the developed method:}

The objective of validation of analytical procedure is to demonstrate whether the procedure is suitable for its intended purpose. The proposed method was validated for various parameters such as Linearity, Accuracy, Precision, Limit of detection (LOD) and Limit of Quantitation (LOQ) according to ICH Q2 (R1) guideline. ${ }^{10}$ 11 
Table 01: Linearity results of Olmutinib in methanol

\begin{tabular}{|c|c|c|}
\hline $\begin{array}{c}\text { Concentration } \\
(\boldsymbol{\mu g} / \mathbf{m l})\end{array}$ & $\begin{array}{c}\text { Method A } \\
\text { (Area under curve) }\end{array}$ & $\begin{array}{c}\text { Method B } \\
\text { (First order derivative) }\end{array}$ \\
\hline 2 & 0.1723 & 0.00523 \\
\hline 4 & 0.3655 & 0.0105 \\
\hline 6 & 0.5534 & 0.0175 \\
\hline 8 & 0.7430 & 0.0250 \\
\hline 10 & 0.93151 & 0.0310 \\
\hline 12 & 1.10882 & 0.0405 \\
\hline
\end{tabular}

Table 02: Result of Precision

\begin{tabular}{|c|c|c|}
\hline Precision & Method A (\%RSD) & Method B (\% RSD) \\
\hline Repeatability & 0.368 & 0.375 \\
\hline Intraday & 0.546 & 0.548 \\
\hline Interday & 0.784 & 0.872 \\
\hline
\end{tabular}

\section{Linearity:}

Fresh aliquots were prepared from the stock solution $(100 \mu \mathrm{g} / \mathrm{ml})$ in different concentrations. The samples were scanned in UV-visible spectrophotometer against reagent blank. It was found that the selected drug shows linearity between the $2-12 \mu \mathrm{g} / \mathrm{ml}$ (Table 01) and fig 05 .

\section{Repeatability:}

The precision of the method was checked by repeatedly injecting $(\mathrm{n}=6)$ standard solutions of olmutinib $(10 \mu \mathrm{g} / \mathrm{mL})$. Area under curve of each of these solutions was measured in the range of $262-272 \mathrm{~nm}$. Percentage relative standard deviation (\%RSD) was calculated (Table 2).

In first order Spectrophotometry derivative method concentration of the solution was determined by measuring absorbance at $\lambda \min =282.83 \mathrm{~nm}, \lambda \max =256.57 \mathrm{~nm}$ and zero cross $=267.68 \mathrm{~nm}$.
Intermediate precision (reproducibility):

The intra-day and inter-day precision of the proposed method was determined by analysing the corresponding responses 3 times on the same day and on 3 different days over a period of 1 week for 3 different concentrations of standard solutions of olmutinib(6, 8 and $10 \mu \mathrm{g} / \mathrm{mL})$. The results were reported in terms of relative standard deviation (\%RSD). The results were tabulated in (Table 2).

\section{Accuracy (Recovery studies):}

The accuracy for the analytical procedure was determined at $80 \%, 100 \%$ and $120 \%$ levels of standard solution. Area under curve was measured in the range of 262-272nmalso first derivative measured in the range $256.57-282.83 \mathrm{~nm}$ and results were expressed in terms of \% recoveries. Three determinations at each level were performed and \% RSD was calculated. The results were tabulated in (Table 3).

Table 03: Recovery Study of Olmutinib

\begin{tabular}{|c|c|c|c|c|}
\hline Accuracy level & $\begin{array}{c}\text { Method A } \\
\text { Mean \% recovery }\end{array}$ & \%RSD & $\begin{array}{c}\text { Method B } \\
\text { Mean \% recovery }\end{array}$ & \%RSD \\
\hline $80 \%$ & 98.03 & 0.630 & 99.09 & 0.825 \\
\hline $100 \%$ & 99.06 & 0.760 & 98.08 & 0.745 \\
\hline $120 \%$ & 98.29 & 0.648 & 98.25 & 0.798 \\
\hline
\end{tabular}

Table 04: LOD and LOQ of Olmutinib

\begin{tabular}{|c|c|c|}
\hline Method & Method A & Method B \\
\hline LOD & 0.3786 & 0.4958 \\
\hline LOQ & 1.0523 & 1.7525 \\
\hline
\end{tabular}

\section{Limit of detection and Limit of Quantitation:}

The objective of validation of analytical procedure is to demonstrate whether the procedure is suitable for its intended purpose. The proposed method was validated for various parameters such as Linearity, Accuracy, Precision, Limit of detection (LOD) and Limit of Quantitation (LOQ) according to ICH Q2 (R1) guideline. (Table 4)

\section{RESULT AND DISCUSSION:}

In spectroscopic technique was developed simple and specific method for the determination of Olmutinib in bulk form. The generated regression equations were,

$$
\begin{aligned}
\text { Method A }-\int_{272}^{262} A \mathrm{~d} \lambda 0.093 \mathrm{x}+0.011 \mathrm{R}^{2} & =0.999 \\
\text { Method B- } \int_{283}^{256} A d \lambda 0.0 .002 \mathrm{x}+0.0029 \mathrm{R}^{2} & =0.997
\end{aligned}
$$


Where $\int_{272}^{262} A \mathrm{~d} \lambda$ is area under curve between $262-272 \mathrm{~nm}$, $\frac{d A}{d \lambda} \mathrm{is}$ amplitude difference, $\mathrm{x}$ is concentration and $\mathrm{R}^{2}$ is correlation coefficient. The $\mathrm{R}^{2}$ values were 0.999 and 0.997 for Method A and B respectively indicated that developed methods were linear. The proposed methods were found to be precise as \% RSD values for intraday as well as Interday precision were satisfactory. The drug at each of the $80 \%$, $100 \%$ and $120 \%$ levels showed good recoveries that is in the range of 98.00 to $99.00 \%$ for both methods, hence it could be said that these methods were accurate. The LOD and LOQ were calculated as $0.3786 \mu \mathrm{g} / \mathrm{ml}$ and $1.0523 \mu \mathrm{g} / \mathrm{ml}$ for method A and $0.4958 \mu \mathrm{g} / \mathrm{ml}$ and $1.7525 \mu \mathrm{g} / \mathrm{ml}$ for method $B$ respectively. Thus, the developed method is found to be robust and rugged which can be applied as a rapid tool for routine analysis of olmutinib in the bulk and in the pharmaceutical dosage form. The validation parameters for method A and method B are summarized in Table 05.

Table No. 05: Optical Parameters/ Summary of Olmutinib

\begin{tabular}{|l|c|c|}
\hline Parameter & Result for Method A & Result for Method B \\
\hline Range & $262-272$ & $256.57-282.83$ \\
\hline Linearity range & $2-12(\mu \mathrm{g} / \mathrm{mL})$ & $2-12(\mu \mathrm{g} / \mathrm{mL})$ \\
\hline Standard regression equation & $0.093 \mathrm{x}+0.011$ & $0.002 \mathrm{x}+0.0029$ \\
\hline Correlation coefficient $\left(\mathrm{R}^{2}\right)$ & 0.9997 & 0.994 \\
\hline Repeatability & 0.368 & 0.375 \\
\hline Intraday & 0.546 & 0.548 \\
\hline Interday & 0.784 & 0.872 \\
\hline Accuracy (Mean \% Recovery) & 99.06 & 99.09 \\
\hline LOD & 0.3786 & 0.4958 \\
\hline LOQ & 1.0523 & 1.7525 \\
\hline
\end{tabular}

\section{CONCLUSION:}

From the results and discussion, two spectrophotometric methods were developed and validated as per ICH guidelines Q2 (R1). In this paper described for the determination of Olmutinib in bulk is simple, sensitive and reproducible. The proposed methods can be successfully applied for Olmutinib without any interference in quality control.

\section{ACKNOWLEDGEMENTS:}

The authors are grateful to, the Principal and the Management of Kasturi Shikshan Sanstha College of Pharmacy, Shikrapur, Pune. The authors are thankful to Mylan laboratories pvt. Ltd. Hyderabad (India) for providing gift sample.

\section{REFERENCES}

1. Kim, E.S., 2016. Olmutinib: first global approval. Drugs, 76(11), pp.1153-1157.

2. Park, K., Lee, J.S., Lee, K.H., Kim, J.H., Cho, B.C., Min, Y.J., Cho, J.Y., Han, J.Y., Kim, B.S., Kim, J.S. and Lee, D.H., 2016. Olmutinib (BI 1482694; HM61713), an EGFR mutant-specific inhibitor, in T790M+ NSCLC: efficacy and safety at the RP2D.J Clin Oncol, 34(suppl), pp.abstr-9055.

3. Zhang, Z., Guo, X., To, K.K., Chen, Z., Fang, X., Luo, M., Ma, C., Xu, J., Yan, S. and Fu, L., 2018. Olmutinib (HM61713) reversed multidrug resistance by inhibiting the activity of ATP-binding cassette subfamily $\mathrm{G}$ member 2 in vitro and in vivo. Acta pharmaceutica sinica $B, 8(4)$, pp.563-574.

4. Attwa, M.W., Kadi, A.A., Darwish, H.W. and Abdelhameed, A.S., 2018. Investigation of the metabolic stability of olmutinib by validated LC-MS/MS: quantification in human plasma. RSC advances, 8(70), pp.40387-40394.

5. Dudhe P.B., Choudhary E. D. (2018) Development and Validation of First Order Derivative Method for Tenofovir alafenamide in Bulk using UV Visible Spectroscopy,Int. J. ChemTech Res, Vol.11, No.08 pp 267-273 [ISSN: 0974-4290]

6. Dudhe PB, Sonawane AM. Spectrophotometric Determination of Cycloserin in Bulk and Capsule
Dosage form by Area under Curve and First Order Derivative Methods. International Journal of pharmtech Research. 2016;9(8):131-9.

7. Dudhe PB, Kamble MC, Van S, Rajpurohit VJ, Komerwar A, Gondane SJ. Development and Validation of a Spectrophotometric Method for Glibenclamide in Bulk and Tablet Dosage Forms. International Journal of PharmTech Research. 2016;9(2):19-23.

8. PB D, Shelke PS, Chavare PD. Determination of Apixaban from Bulk and Tablet Dosage Form by Area Under Curve and First Order Derivative Spectrophotometric Methods.

9. Dudhe, P.B., Shinde A. P., Salgar K., (2014).Development and validation of analytical methods for Simultaneous estimation of domperidone and esomeprazole Magnesium in bulk and in pharmaceutical formulations Using UV-Visible spectroscopy, Int. J. PharmTech Res, 6, (5), 1501-1508, ISSN No.0974-4304.

10. B. Khandare, P.B. Dudhe, S. Upasani and M. DhokeSpectrophotometric Determination of Vandetanib in Bulk by Area Under Curve and First Order Derivative Methods, International Journal of PharmTech Research, 2019, 12(02), 103-110.

11. Balu S. Khandare,Nikhil S. Bhujbal and Sandip S. Kshirsagar . Analytical Method Development and Validation of Vandetanib by Using RP-HPLC of Bulk Drug. Scholars Academic Journal of Pharmacy.8(8): 432-435

12. PB D, Kamble MC, Komerwar A, Sonawane AM, Van S. Development and validation of first order derivative method for Metronidazole in bulk and tablet using UV Visible spectroscopy.

13. Dudhe, P.B., Shivarkar N. A., Nagras M. A., (2012). UVSpectrophotometric method development and validation of propranolol hydrochloride and flunarizinedihydrochloride in bulk drug and capsule dosage form, Contemporary Investigations and Observations in Pharmacy,1(1), 19-23, ISSN No.22787429.

14. P.B Dudhe, Lahane AV, Borhade KD, Shelke PS, Chavare PD. Spectrophotometric Determination of Acetazolamide in Bulk and Tablet Dosage Form by Area Under Curve and First Order Derivative Methods. 
15. Dudhe P.B., Chavare P. D., Shelke P. S. (2017) Spectrophotometric Determination of Febuxostat from Bulk and Tablet Dosage Form by Area Under Curve Method,Int. J. ChemTech Res, Vol.10, No.06 pp 183189 [ISSN: 0974-4290]

16. Dudhe PB, Kamble MC. RP-HPLC Method Development and Validation forthe Determination of Canagliflozin in Human Plasma.

17. Sonawane A.M, Dudhe P.B, Chalke NH, Bhagat KB. development and validationrp-HPLC method for the simultaneous determinetion of loperamide hydrochloride and norfloxacin in pharmaceutical formulation. International journal of pharmaceutical sciences and RESEARCH. 2016 Aug 1 ;7(8):3441-5.

18. Manoj Dhoke Sachi Upasani, Prashik Dudhe, Balu Khandare. Development and Validation of Adenosine by RP-HPLC Method in Bulk drug and Pharmaceutical dosage forms. Am. J. PharmTech Res, 2019; 9(3), 240246. 